disease was found by her. Our first investigations permitted the distinction of certain groups of cells, one consisting of Sternberg-Reed cells and the other of large moderately basophilic blast-like cells, which we considered to be typical for patients with Hodgkin's disease. Morphological examination and staining procedures by light microscopy showed some characteristics that resembled those of so-called Hodgkin cells in lymph nodes.

In contrast to Bouroncle (1966) we found a correlation between the presence of these characteristic cells and the Hodgkin lesions of the spleen. This could indicate that splenic involvement is not due to lymphogenic dissemination of the disease. Ripault and Dumont (1971) have already pointed out that retrograde lymphatic spread is not the most probable pathway for involvement of the spleen. The correlation mentioned above makes haematogeneous spread more likely in these cases. Vascular invasion in lymph nodes has been described (Rappaport and Strum, 1970; Strum et al., 1971), and Rappaport and Strum indicated the increased risk of the occurrence of extranodal or non-adjacent lymphoid involvement in the disease. Even if the cells are wandering from the spleen to other organs it still means that the disease is not restricted to lymphoid organs any more.

As the exact nature of these cells has not been elucidated it is also possible that both features indicate a role in a multicentric origin of the disease or the influence of a lymphotropic agent as mentioned by Teillet (1971) and others.

All possibilities throw doubt on the validity of the Rye classification of the clinical stages in Hodgkin's disease and on its principles of unicentric origin and lymphogenic contiguous spread, on which the extensive irradiation regimen was founded by Kaplan (1966) and others. In cases as described above this method leaves a high risk of dissemination of the disease to non-adjacent and at that moment non-irradiated areas. Indeed this could be an explanation for some of the unexpected disappointing results in the treatment of patients with splenic
Hodgkin's disease by irradiation (Halie et al., 1972). Generalized therapy - for instance, with chemotherapeutic agents or perhaps low-dose irradiation of large fields-is then preferable.

This work was supported by a grant from the Stichting Koningin Wilhelmina Fonds, Nederlandse Organisatie voor de Kankerbestrijding. We gratefully acknowledge the skilled technical help of Miss W. Huiges and Miss W. Schuurmans. We thank Professor J. Oldhoff and his staff, Department of Surgery, for their co-operation. Professor A. Arends carried out the histological procedures and classified the tissue specimens taken at laparotomy.

Requests for reprints should be addressed to Dr. M. R. Halie, Division of Haematology, Department of Medicine, University Hospital, Oostersingel 59, Groningen, The Netherlands.

\section{References}

Bouroncle, B. A. (1966). Blood, 27, 544

Crowther, W., Hamilton Fairley, G., and Sewell, R. L. (1968). British

Fournal of Haematology, 15, 321 .
Glatstein, E., Guernsey, J. M., Rosenberg, S. A., and Kaplan, H. S. (1969). Cancer (Philadelphia), 24, 709.

Halie, M. R., Seldenrath, J. J., Stam, H. C., and Nieweg, H. O. (1972). British Medical fournal, 2, 611 .

Kaplan, H. S. (1966). Cancer Research, 26, 1221

Lowenbraun, S., Ramsey, H., Sutherland, J., and Serpick, A. A. (1970) Annals of Internal Medicine, 72, 655.

Lukes, R. J., and Butler, J. J. (1966). Cancer Research, 26, 1063.

Lukes, R. J., Craver, L. F., Hall, T. C., Rappaport, H., and Rubin, R. (1966). Cancer Research, 26, 1311

Peters, M. V. (1966). Cancer Research, 26, 1232.

Rappaport, H., and Strum, A. B. (1970). Cancer (Philadelphia), 25, 1304.

Ripault, J., and Dumont, J. (1971). Actualités Haematologiques, ed. J. Bernard, 5th series, p. 52. Paris, Masson.

Rosenberg, S. A. (1966). Cancer Research, 26, 1310.

Rosenberg, S. A., and Kaplan, H. S. (1966). Cancer Research, 26, 1225.

Stofberg, A. M. M. (1962). Thesis, Groningen, Deventer, N. V. Drukkerij Salland.

Stofberg, A. M. M. (1963). Acta Haematologica, 29, 65.

Strum, A. B., Hutchison, G. B., Park, J. K., and Rappaport, H. (1971) Cancer (Philadelphia), 27, 1 .

Teillet, F. (1971). Actualités Haematologiques, ed. J. Bernard, 5th series, p. 68. Paris, Masson.

\title{
Curative Radiotherapy in Hodgkin's Disease: Significance of Haematogenous Dissemination Established by Examination of Peripheral Blood and Spleen
}

\author{
M. R. HALIE, J. J. SELDENRATH， H. C. STAM， H.O. NIEWEG
}

British Medical fournal, 1972, 2, 611-613

\section{Summary}

Studies of peripheral blood leucocyte concentrates in patients with Hodgkin's disease showed two types of cells believed to be typical for the disease in a number of patients. Involvement of the spleen as diagnosed after splenectomy and histological examination showed a close correlation with the presence of these characteristic cells in the peripheral blood. This is believed to be an argument for haematogenous spread or a multicentric origin of the disease in these cases. The results of attempted curative high-voltage radiotherapy with total node irradiation in 24 patients seem to support this concept. On the basis of

University of Groningen, The Netherlands

M. R. HALIE, M.B., Senior Scientific Officer, Division of Haematology

J. J. SELDENRATH, M.B., Former Senior Scientific Officer, Division of Radiotherapy

H. C. STAM, M.D., Professor of Radiotherapy

H. O. NIEWEG, M.D., Professor of Haematology

the Rye classification of clinical stages the results of radiotherapy are not predictable. Six patients in stage II and seven in stage III were in remission, one in each of stages II and IV, and six in stage III had recurrences of the disease within one year. A division into localized or disseminated forms of the disease based on the investigations of blood and spleen showed all localized cases in remission; of the disseminated cases one reached a remission and all others had recurrences. In three patients the therapy could not be cempleted. These preliminary treatment results are believed to support the idea of a special role of the spleen in the dissemination of the disease. A new classification of clinical stages in Hodgkin's disease is proposed.

\section{Introduction}

The principles of unicentric origin and lymphatic spread in Hodgkin's disease, as formulated by Kaplan (1968) and others, have led to the application of radiotherapy on both involved 
and contiguous apparently healthy lymph node areas (Peters, 1966; Rosenberg, 1966). Good results with this approach in stages I and II of the disease according to the Rye classification have prompted total node irradiation in more advanced stages of the disease (Johnson, 1969). In these cases the attempts at curative treatment have been disappointing. The possibility of non-contiguous involvement or spread has been mentioned (Johnson, 1969). Cytological and histological examinations of the peripheral blood and spleen have provided support for the idea of a haematogenous dissemination or multicentric origin (Halie et al., 1972). This report compares retrospective analysis of the results of attempted curative radiotherapy in our series based on the Rye classification and on a classification based on examination of the spleen and peripheral blood.

\section{Materials and Methods}

The diagnosis of Hodgkin's disease was made on the basis of a lymph node biopsy. The histological classification was based on the criteria of the nomenclature committee of the Rye conference 1965 (Lukes and Butler, 1966; Lukes et al., 1966). Each patient was investigated by physical examination, blood and urine profiles, bone marrow biopsy, liver function tests, and scanning procedures of the liver and spleen with colloidal ${ }^{90 \mathrm{~m} T c}$, abdominal lymph nodes with ${ }^{75} \mathrm{Se}$-selenomethionine, and bones with ${ }^{85} \mathrm{Sr}$ or ${ }^{87 \mathrm{~m} S r}$. Chest $x$-ray examination, lymphography, intravenous pyelography, and $x$-ray examination of the bones were also carried out. Leucocyte concentrates of the peripheral blood were prepared according to Stof berg (1963) except that edetic acid $3 \% 1: 10$ was substituted for heparin. The smears were stained with May-Grünwald-Giemsa and other stains and were examined for the presence of abnormal cells, especially the rarely occurring typical Sternberg-Reed cells and a category formed by moderately basophilic blast-like cell with a diameter $>15 \mu \mathrm{m}$, a nucleus varying in appearance with somewhat reticulated chromatin, and one to three large nucleoli.

Initially patients considered suitable for curative radiotherapy were not subjected to laparotomy, but later this was always performed with splenectomy, wedge-biopsy of the liver, and, if possible, a lymph node biopsy. The tissues were examined for Hodgkin lesions and imprint preparations were made in the haematology laboratory.

The dissemination of the disease before laparotomy was expressed according to the classification adopted at the Rye conference (Rosenberg, 1966). In the subdivision of A and B categories the criteria of the symposium on the staging of Hodgkin's disease held in April 1971 were followed (Carbone et al., 1971).

A simultaneous study (Halie et al., 1972) had indicated that splenic involvement was probably associated with haematogenous dissemination, thus the extent of the disease was described after laparotomy as "localized" when confined to lymph nodes only or as "disseminated" when the spleen or other organs or both contained Hodgkin foci.

Radiotherapy was given to the diseased lymph nodes and their adjacent areas as described by Vera Peters (1966) and Kaplan and Rosenberg (1966). A Tele-Cobalt unit (Gammatron, Siemens, West Germany) was used in all curative therapy attempts. In some cases the head and neck and mediastinal and axillary glands were irradiated in a single so-called mantle field (van Dorssen et al., 1970), but when abnormal cervical lymph nodes were present each side of the head and neck region was irradiated separately to ensure treatment of the upper cervical lymph nodes. The total doses for the supradiaphragmatic fields were usually 3,600 to 4,000 rads over a period of five to six weeks. Abdominal irradiation was done by a moving-strip technique (Moss, 1965) in which the right upper quadrant (including the upper pole of the right kidney) of the abdomen was spared.

\section{Results}

From 1969 to early in 197117 patients underwent curative radiotherapy with total node irradiation-that is, of lymph nodes from the head, neck, axillae, mediastinum, and the abdomen, including the inguinal regions. A comparison of the results with the clinical stages of the Rye classification and with our own classification based on the dissemination concept of spleen and peripheral blood involvement is summarized in Table $I$.

TABLE I-Results of Attempted Total Node Irradiation in 17 Patients

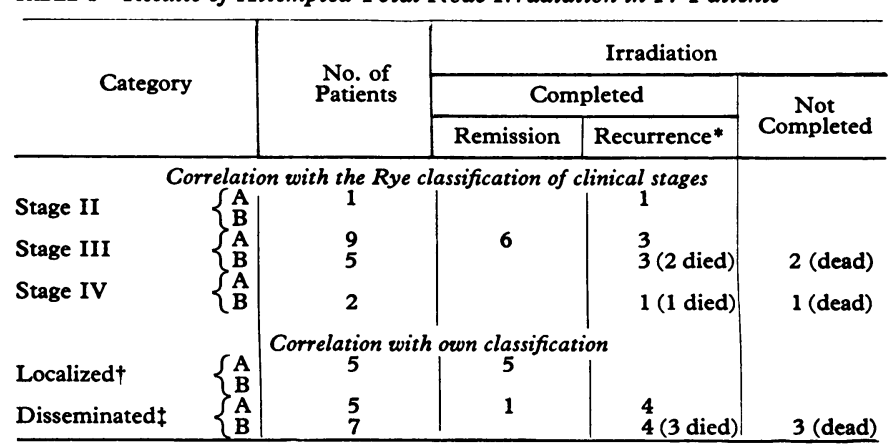

*All recurrences occurred within one year after completion of radiotherapy. †Based on blood and spleen examinations in three patients, and on blood only in

$\ddagger$ tased on blood and spleen examinations in 10 patients, and on blood only in two patients.

One patient with involvement of inguinal and high abdominal lymph nodes as well as of the spleen was regarded as having clinical stage II disease, though in our classification this was regarded as disseminated. The two patients in stage IV had a parahilar lung focus that could easily be incorporated in the irradiation field of the mediastinum.

In stage III of Hodgkin's disease a prognosis based on the Rye staging procedure is particularly unreliable. On the other hand, in patients with localized forms of the disease on our classification therapy has so far been successful, whereas only one patient with disseminated disease on our classification was in remission one and a half years after completion of therapy. Recurrences were found mostly in the non-irradiated areas, such as the liver and the lungs, but also in the bones previously covered by one of the irradiation fields.

An analysis of patients who had had an attempt at a complete course of curative radiotherapy up to the time of writing is given in Table II. The results indicate that most patients in

TABLE II-Results in 24 Patients Treated by Curative Irradiation During N Period of Study

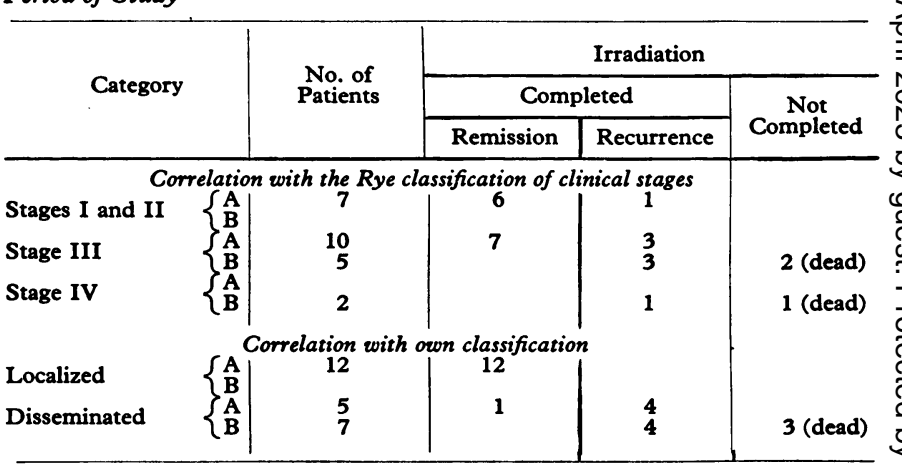

stages I and II of the Rye classification have truly localized forms of the disease but that in stage III absence of splenic Hodgkin lesions and lack of abnormal peripheral blood cells are an indication for good results of radiotherapy. Patients with general symptoms must be regarded as having a bad prognosis in both classifications. 
T ABLE III-Correlation of Histological Classification, Clinical Stages, and Results of Radiotherapy

\begin{tabular}{|c|c|c|c|c|c|c|c|c|c|c|c|c|}
\hline & & & & \multicolumn{4}{|c|}{ Rye Staging } & \multicolumn{2}{|c|}{ Own Classification } & \multicolumn{3}{|c|}{ Radiotherapy } \\
\hline & & & & I & II & III & IV & Localized & Disseminated & $\begin{array}{c}\text { Not } \\
\text { Completed }\end{array}$ & Remission & Recurrence \\
\hline $\begin{array}{l}\text { Lymphocytic predominance } \\
\text { Nodular sclerosis } \ldots\end{array}$ & $\begin{array}{l}\cdots \\
\cdots \\
\cdots \\
\cdots\end{array}$ & $\begin{array}{l}\cdots \\
\cdots \\
\cdots\end{array}$ & $\begin{array}{l}\cdots \\
\cdots \\
\cdots \\
\cdots\end{array}$ & 1 & $\begin{array}{l}2 \\
3 \\
1\end{array}$ & $\begin{array}{l}2 \\
5 \\
6 \\
2\end{array}$ & $\begin{array}{l}1 \\
1\end{array}$ & $\begin{array}{l}4 \\
8\end{array}$ & $\begin{array}{l}2 \\
7 \\
2 \\
1\end{array}$ & $\begin{array}{l}1 \\
2\end{array}$ & $\begin{array}{l}4 \\
8 \\
1\end{array}$ & $\begin{array}{l}1 \\
6 \\
1\end{array}$ \\
\hline
\end{tabular}

Histological classification can aid prognosis but the correlation with the clinical course of the disease under therapy is not absolute (Table III).

\section{Discussion}

The usual approaches to the treatment of Hodgkin's disease consist in either radiotherapy or the application of one or more cytostatic drugs. In stages I and II of the disease according to the Rye classification high-voltage irradiation is the treatment of choice, but not in stages III and IV. Theoretically, in stage III irradiation of all reticuloendothelial organs should give good results when the basic concept of unifocal origin of the disease and lymphatic spread is true. Reports from trials, however, indicate results that are in no way comparable to those of radiotherapy in stages I and II (Amiel, 1971). Even in these two stages there is already a recurrence rate of about $40 \%$; possibly that could be explained by a non-contiguous involvement of lymphoid tissues (Johnson, 1969). The importance of the role of the spleen in the origin or spread of the disease was also proposed by Teillet (1971). In our investigations two kinds of abnormal cells thought to be typical of Hodgkin's disease were found in the peripheral blood in the same patients who had Hodgkin tissue in the spleen. This correlation is believed to be an indication of a multicentric origin of the disease or of a haematogenous dissemination in these cases. When the results of attempted curative radiotherapy are reviewed it is not possible to predict these results on the clinical staging classification of the Rye conference 1965. Especially in stage III A it cannot be foreseen which patient is going to benefit from total node irradiation and which one is not. For the patients of the B category with general symptoms the bad prognosis is not likely to be changed by attempts at curative radiotherapy. When a distinction is made between localized (confined to lymph nodes) and disseminated forms of the disease, based on examination of leucocyte concentrates and the spleen, the results of curative radiotherapy were much more consistent.

All localized cases are in remission and with one exception all disseminated cases had recurrences within one year. In our opinion these findings support the concept of the important role of the spleen in the distinction between restriction of the disease to the lymph nodes or dissemination. An appropriate choice of the method of treatment can probably be made on this basis. The Rye classification of clinical stages gives insufficient information concerning the true state of dissemination of the disease so long as the spleen is believed to be another lymphoid organ. Therefore a new division of Hodgkin's disease is proposed. Localized forms: stage I, disease confined to one or more contiguous lymph nodes on one side of the diaphragm; stage II, spread to lymph nodes on both sides of the diaphragm. Disseminated forms: stage III, involvement of lymph nodes and spleen; stage IV, involvement of lymphoid and parenchymatous organs.

Subdivision into A and B categories, without or with general symptoms, can be made according to the criteria of the Ann Arbor conference on Hodgkin's disease (Carbone et al., 1971).

In the localized forms of the disease an attempt at curative therapy can be made with irradiation. In our opinion curative radiotherapy is not likely to succeed in the disseminated form, in which treatment with cytostatic drugs and, when necessary, palliative irradiation is recommended.

The lymph node biopsies were performed by Dr. R. Eibergen and Professor A. Arends, of the department of pathology. This work was supported in part by a grant from the Stichting Koningin Wilhelmina Fonds, Nederlandse Organisatie voor de Kankerbestrijding.

\section{References}

Amiel, J. L. (1971), Union Internationale Contre le Cancer: Course on Cancer Chemotherapy, Curacao, October 1971.

Carbone, P. P., Kaplan, H. S., Musshoff, K., Smithers, D. W., and Tubiana, M. (1971). Cancer Research, 31, 1860.

Dorssen, J. G. van, Mellink, J. H., and Thomas, P. (1970). Radiologia Clinica et Biologica, 37, 47 .

Halie, M. R., Eibergen, R., and Nieweg, H. O. (1972). British Medical fournal, 2, 609 .

Johnson, R. E. (1969). Leukemia and Lymphoma, ed. J. F. Holland, P. A. Miescher, and E. R. Jaffe, p. 133. New York, Grune \& Stratton.

Kaplan, H. S. (1968). New England fournal of Medicine, 278, 892.

Kaplan, H. S., and Rosenberg, S. A. (1966). Cancer Research, 26, 1268

Lukes, R. J., and Butler, J. J. (1966). Cancer Research, 26, 1063.

Lukes, R. J., Craver, L. F., Hall, T. C., Rappaport, H., and Rubin, R. (1966). Cancer Research, 26, 1311.

Moss, W. T. (1965). Therapeutic Radiology, p. 376. Saint Louis, Mosby.

Moss, W. T. (1965). Therapeutic Radiology, p. 376.

Peters, M. V. (1966). Cancer Research, 26, 1232.
Rosenberg, S. A. (1966). Cancer Research, 26, 1310.

Stofberg, A. M. M. (1963). Acta Haematologica, 29, 65. Teillet, F. (1971) in Actualités Hématologiques, J. Bernard, 5th series, p. 68.
Paris, Masson. 